\title{
NIVEL DE AUTOCUIDADO EN LOS ESTUDIANTES DE PRIMER INGRESO DE LA ESCUELA NACIONAL DE ENFERMERIA Y OBSTETRICIA EN MÉXICO, D.F.
}

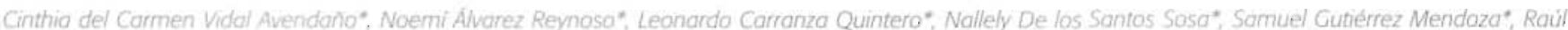
Ladrón de Guevara Sánchez", Juan Pablo Magdaleno Medina*; Susano Pérez Hernandez; Lucero Romano Almanza*, Melba Vázquez Ramirez*, Josué Velazquez Meza". Asesora Maestra Lasty Balseira Almario*

* Alumnos del grupo 1104 de la Licenciatura de Enfermería y Obstetricia del tumo matutino

* Profesora de Correra Titular " $B$ " de la ENEO

\section{RESUMEN}

El objetivo del presente trabajo es analizar el nivel de Autocuidado de los alumnos de primer ingreso de la Escuela Nacional de Enfermerla y Obstetricia en México, DF. El Autocuidado es una acción de las personas maduras y en proceso de maduración que han desarrollado las capacidades para actuar intencionalmente para regular los factores que afectan su propio funcionamiento y desarrollo. Según Dorotea E. Orem, la teoría de Enfermería sobre el déficit de Autocuidado es una sintesis de los conocimientos sobre las entidades teóricas del Autocuidado, la demanda del Autocuidado terapéutico, la entidad relacional del déficit de Autocuidado y la agencia de Enfermeria. Esta teoria general de Enfermería se expresa en términos de las entidades teóricas mencionadas e introduce afirmaciones existentes entre ellas, tales como adultos maduros comprometidos en el Autocuidado. Los requisitos del Autocuidado son reflexiones formuladas y expresadas sobre las acciones que se sabe son necesarias o que se supone que tiene validez en la regulación de aspectos del funcionamiento y desarrollo humano. Se entiende por requisito algo que es necesario o indispensable para llevar a cabo una acción especifica. De esta manera, un requisito de Autocuidado se considera al conjunto de acciones encaminadas a mejorar aquellas condiciones humanas como son: la función adecuada del organismo y el desarrollo sociocultural del individuo, de tal forma que cumpla con el cuidado propio de la salud.

Metodología: Esta es una investigación diagnóstica, analítica, descriptiva, observacional y prospectiva, llevada a cabo en la ENEO, de octubre a diciembre de 2005. De manera convencional se entrevistaron a 282 alumnos de primer ingreso a la Licenciatura de Enfermeria y Obstetricia en la ENEO y que aceptaron resolver los cuestionarios de forma anónima. Se identificaron los diversos niveles de Autocuidado mediante el cuestionario aplicado que estuvo integrado por 17 preguntas cerradas estructuradas conforme a los indicadores de la variable estudiada.

Resultados: Se pudo constatar que el $95.40 \%$ de los alumnos oscila en edades de 17 a 24 años, el $74.47 \%$ son de sexo femenino, el $87.59 \%$ son solteros (as), el $70.57 \%$ son de religión católica y el $34.76 \%$ vienen del $\mathrm{CCH}$ de la UNAM. En relación con los datos que miden la variable Autocuidado se encontró que el $58.80 \%$ de los alumnos no hacen ejercicio porque están cansados o porque no tienen tiempo, el 97.27\% realizan su aseo personal exhaustivamente todos los dias porque de esa forma mantienen su Autocuidado, el $74.47 \%$ consideran que su salud dental va de buena a excelente porque consultan el Dentista por lo menos cada 6 meses, el $52.84 \%$ piensan que su alimentación es regular porque consumen alimentos chatarra y no tienen una dieta balanceada, el $64.55 \%$ se consideran personas tranquilas que manejan bien las tensiones y de esa forma controlan el estrés, el $82.28 \%$ previenen accidentes para mantener su Autocuidado, el 64.54\% previenen enfermedades porque se autocuidan, el $74.12 \%$ duermen entre 6 y 8 horas y con eso les basta para descansar, el $49.29 \%$ están informados de las medias de seguridad de la escuela para mantener su Autocuidado, el 60.30\% consideran que su funcionamiento gastrointestinal es bueno ya que se mantienen sin colitis, gastritis u otro tipo de disfunción, el $68.16 \%$ buscan recrearse en las horas de ocio ya que van al cine, ven televisión y estos los combinan con sus horas de estudio y el $63.83 \%$ consideran que su Autocuidado es muy bueno.

PALABRAS CLAVE: Autocuidado, teoria de Enfermería, Alumnos, Investigación. 


\section{ABSTRACT.}

The object of the present paper is analyzing the self-care level of the freshman students at the National School of Nursing and Obstetrics in Mexico, D.F. Self-care theory. Self-care is an action of mature and mature in process people who have develop abilities for intentionally act in order to regulate factors affecting their own functions and development. According to Dorotea E. Orem, self-care nursing theory is a knowledge synthesis about self-care theoretical entities, therapeutic self-care demand, the regional entity of self-care deficit and the nursing agency. This nursing general theory is expressed on the mentioned theoretical entities terms and introduces the existing statements among them, such as mature adults engaged on self-care. Self-care requisites are formulated and expressed reflections about those actions known as necessary or that supposedly have validity for regulating functioning and human development aspects. By requisite it is understood something that is necessary or indispensable to carry out a specific action. So a self-care requisite can be consider the array of actions driven to enhance those human conditions as the adequate function of the organism and individual's social-cultural development, in such a way that it fulfils the own health care.

Methodology: This is a diagnostic, analytical, descriptive, observational and prospective research carried out at ENEO, from October to December, 2005. In a conventional way 282 freshmen students to nursing career at ENEO were interviewed, and they accepted solving questionnaires anonymously. Several self-care levels were identified by the applied questionnaire that was constructed by 17 closed questions structured according to the studied variable indicators.

Outcomes: It could be stated that $95.40 \%$ of the pupils ranges 17 to 24 years old, are women, $87.59 \%$ are single, $70.57 \%$ are catholic, and $34.76 \%$ come from CCH-UNAM schools. In relation to dato that measure self-care variable, $58.80 \%$ of the pupils do no physical exercise because they are tired or don't have time; $97.27 \%$ carry out their personal cleaning exhaustively daily because that's the way they keep up their self-care; $74.47 \%$ consider their dental health ranges from good to excellent because they meet the dentist at least every 6 months; $52.84 \%$ think their diet practice is regular, they consume snacks and don't have a balanced diet; $64.55 \%$ consider themselves calm quiet persons who handle tensions well and thus control stress; $82.28 \%$ prevent accidents for maintaining their self-care; $64.54 \%$ prevent diseases because they practice their self-care; $74.12 \%$ sleep 6 to 8 hours and that is enough for them to rest; $49.29 \%$ are informed about the school security measures for maintaining self-care. The $60.30 \%$ consider their gastro-intestinal functioning is good since they don't suffer colitis, gostritis, or other malfunction type: $68.16 \%$ look for recreation in their spare hours so they go to the movies, watch T.V., and combine those with their study schedules, and $63.83 \%$ consider their self-care is good.

KEY WORDS: Self-care, nursing theory, pupils, research.

\section{INTRODUCCIÓN}

La presente investigación tiene como objeto conocer el nivel de Autocuidado que tienen los alumnos de primer ingreso de la Escuela Nacional de Enfermería y Obstetricia (ENEO) en México, DF.

La ENEO es una organización de salud que forma profesionales de Enfermería a nivel Licenciatura y Postgrado, la escuela recibe alrededor de 500 alumnos de primer ingreso en sus turnos matutino y vespertino anualmente, entre los que destacan los alumnos de la Licenciatura.
Se ha observado que los hábitos de Autocuidado que tienen los estudiantes de primer ingreso son deficientes y que esto ha dado lugar a diversos padecimientos de los cuales es importante mencionar algunos como: caries por falta de visitas al Dentista, carencia de actividades deportivas, no se presentan a chequeos médicos frecuentes, se presentan enfermedades nutricionales tales como son: obesidad, bulimia, anorexia, etc. Asi mismo, se presentan alumnos con un deficiente aseo personal, con estrés por el estudio, con falta de sueño y problemas de reposo. 
Problema: El problema de estudio se puede identificar de la siguiente forma: ¿Cuál es el nivel de Autocuidado en los estudiantes de primer ingreso en la Escuela Nacional de Enfermeria y Obstetricia en México, DF?

Justificación: Esta investigación se realizó porque: en primer lugar no existe un estudio similar que se enfoque al problema de Autocuidado de los alumnos. En segundo lugar porque beneficia a los alumnos de la ENEO, el que las Autoridades de la Escuela se preocupen en mantener el Autocuidado integral en su población estudiatil.

Objetivos: Los objetivos de esta investigación se dividen en general y específicos. El objetivo general fué Analizar el nivel de Autocuidado en los alumnos de primer ingreso de la ENEO en México, DF. Los objetivos específicos fueron: Identificar los tipos de Autocuidado y Proponer diversas medidas para mejorar el Autocuidado en los alumnos de nuevo ingreso de la ENEO en México, DF.

\section{METODOLOGIAA}

El tipo de investigación que se realizó es diagnóstica, analítica, descriptiva, observacional y prospectiva.El diseño de investigación se realizó atendiendo diferentes aspectos.

- Asistencia a un curso de Metodología de la Investigación en las instalaciones de la ENEO.

- Búsqueda de un problema de investigación con aportación a Enfermería.

- Asistencia a la biblioteca en varias ocasiones para buscar el marco teórico conceptual y referencial de la variable Autocuidado.

- Elaboración del instrumento o cuestionarios con base en los indicadores para medir la variable Autocuidado.

- Aplicación del instrumento a la muestra seleccionada

- Captura, recuento y clasificación de los datos en tarjetas simples, de concentración y matrices.

- Elaboración de conclusiones y recomendaciones, así como el informe final de la investigación.

Variable e indicadores

Variable: autocuidado e indicadores: Aseo personal, salud dental, actividad de reposo, eliminación, prevención de enfermedades, alimentación, actividad de sueño, prevención de accidentes, presencia de estrés, seguridad y ejercicio.

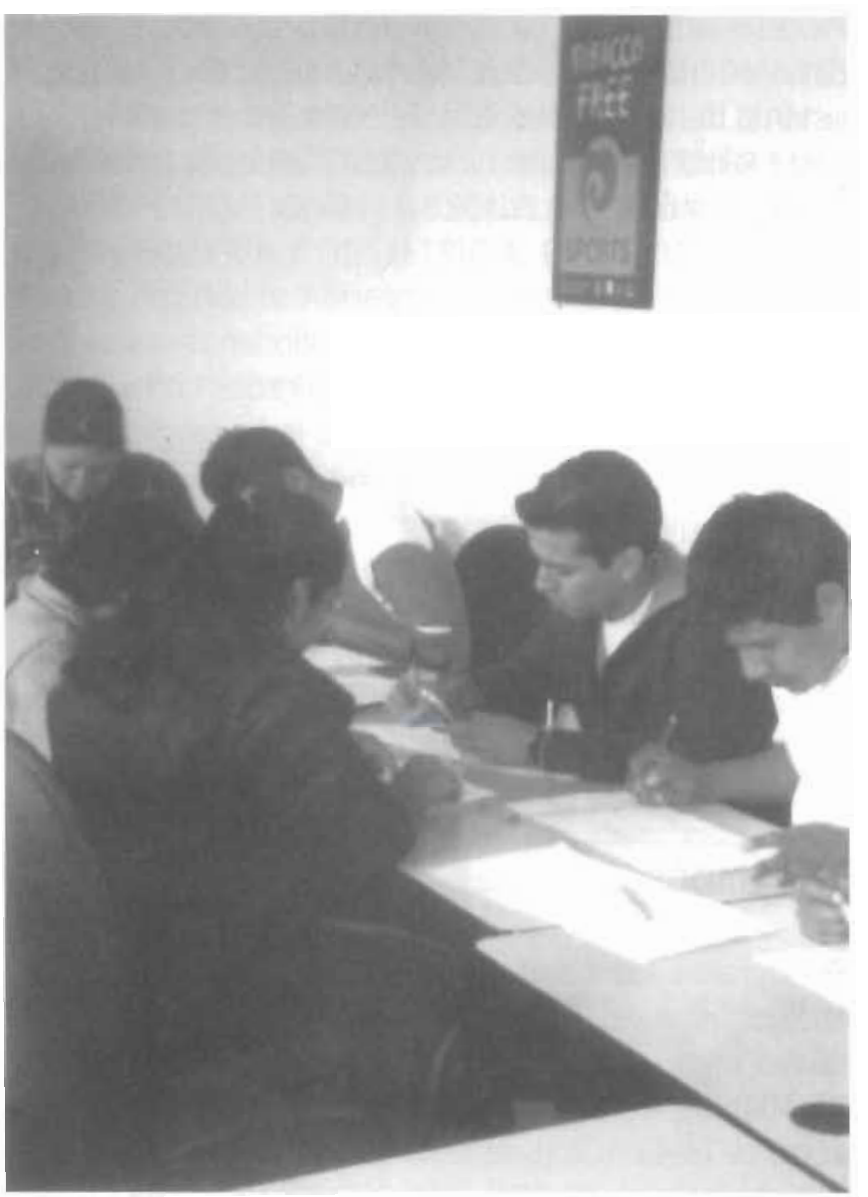

Universo, población y muestra: El universo representa el $100 \%$ del fenómeno de estudio, para la ENEO, existen alrededor de 3020 alumnos, en los turnos matutino y vespertino. Estos alumnos son de diferentes modalidades. Ejemplo: Licenciatura, nivel técnico, SUA, posgrado, etc. La población fué una parte importante del universo. La población la constituyeron todos los alumnos del primer semestre de la carrera, que fueron alrededor de 407 del turno matutino y vespertino de primer ingreso. La muestra fue el $100 \%$ de la población, es decir, los alumnos de la licenciatura de primer semestre que fueron alrededor de 407 alumnos. Esta muestra representó el $13.47 \%$ del universo. Cabe mencionar que de los 407 alumnos, sólo pudieron ser encuestados 282 alumnos.

Criterios de inclusión, exclusión y eliminación: Elaboración del criterio de inclusión para todos los alumnos de primer ingreso a la Licenciatura de Enfermería y Obstetricia. Elaboración del criterio de exclusión para los alumnos que no cursan el primer semestre a la Licenciatura de Enfermeria y Obstetricia. Elaboración del criterio de eliminación para aquellos alumnos del primer semestre que no participaron en las encuestas y por tanto, no quisieron contestar los cuestionarios. 
Proceso estadístico de datos: El proceso estadístico de. datos se hizo de manera manual utilizando para ello el sistema de tarjetas simples, de concentración y matrices, para realizar el recuento, la captura y la clasificación de los datos y tabularlos en cuadros y gráficas.

Aspectos éticos: En esta investigación se han considerado los aspectos éticos, ya que los cuestionarios aplicados a los alumnos fueron anónimos y explicados con anterioridad informándoles en qué consistia la investigaciỏn, con lo que se contó con su amplia colaboración. También se les indicó que los resultados estarian a su disposición en el momento que ellos quisieran. Todos los cuestionarios fueron de carácter anónimo respetando la confidencialidad y la individualidad de cada uno de los alumnos entrevistados. De esta manera no se atentó contra la individualidad de los alumnos y se respetó en todo momento su decisión de cómo contestar los cuestionarios.

\section{RESULTADOS}

Se lograron los objetivos de la investigación al poder analizar el nivel de Autocuidado de los alumnos de nuevo ingreso de la ENEO. Se pudo constatar que el $95.40 \%$ de los alumnos oscilan en edades de 17 a 24 años, el $74.47 \%$ son de sexo femenino, el $87.59 \%$ son solteros(as), el $70.57 \%$ son de religión católica y el $34.76 \%$ vienen del $\mathrm{CCH}$ de la UNAM. En relación con los datos que miden la variable Autocuidado, el 58.80\% de los alumnos no hacen ejercicio, porque están cansados o porque no tienen tiempo (ver gráfica $N^{0} 1$ ), el $97.27 \%$ realizan su aseo personal exhaustivamente todos los días porque de esa forma mantienen su Autocuidado, el $74.47 \%$ consideran que su salud dental va de buena a excelente porque consultan al dentista por lo menos cada 6 meses, el 52.84\% piensan que su alimentación va de regular a pésima ya que tienen una alimentación regular, consumen alimentos chatarra y no tienen una dieta balanceaḍa (ver gráfica $N^{\circ} 2$ ), el $64.55 \%$ se consideran personas tranquilas que manejan bien las tensiones y de esta forma, controlan el estrés, el $82.28 \%$ previenen accidentes para mantener su Autocuidado, el 64.54\% previenen enfermedades porque se autocuidan (ver gráfica $N^{\circ} 3$ ), el 74.12\% duermen entre 6 y 8 horas y con eso les basta para descansar, el $49.29 \%$ están informados de las medidas de seguridad de la escuela para mantener su Autocuidado. De igual forma, el $60.30 \%$ consideran que su funcionamiento gastrointestinal es bueno ya que se mantienen sin colitis, gastritis u otro tipo de disfunción, el 68.16\% buscan recrearse en sus horas de ocio ya que van al cine, ven televisión y estos los combinan con sus horas de estudio (ver gráfica $N^{\circ} 4$ ) y finalmente el 63.83\% consideran que su Autocuidado es bueno. De los 11 indicadores medidos de la variable Autocuidado se pueden considerar, positivos el de aseo personal, de salud dental, el de prevención de estrés, prevención de accidentes, prevención de enfermedades, horas que duermen al día, conocimientos de las medidas de seguridad de la escuela, funcionamiento gastrointestinal y realización de actividades recreativas. Se consideran negativos los indicadores: realización del ejercicio y alimentación. Lo anterior, significa que al contar los alumnos con indicadores medidos más positivos que negativos, su Autocuidado resulta ser también positivo, lo que está acorde con las medidas tomadas en la escuela en el primer semestre, para mantener la salud integral de los alumnos.

\section{GRÁFICA N ${ }^{\circ} 1$}

\section{DISTRIBUCIÓN DE LA OPINIÓN DE LOS ESTUDIANTES DE PRIMER INGRESO, EN TORNQ A SI HACEN EJERCICIO PARA MANTENER SU AUTOCUIDADO, EN LA ESCUELA NACIONAL DE ENFERMERÍA Y OBSTETRICIA, EN MÉXICO, D.F.}

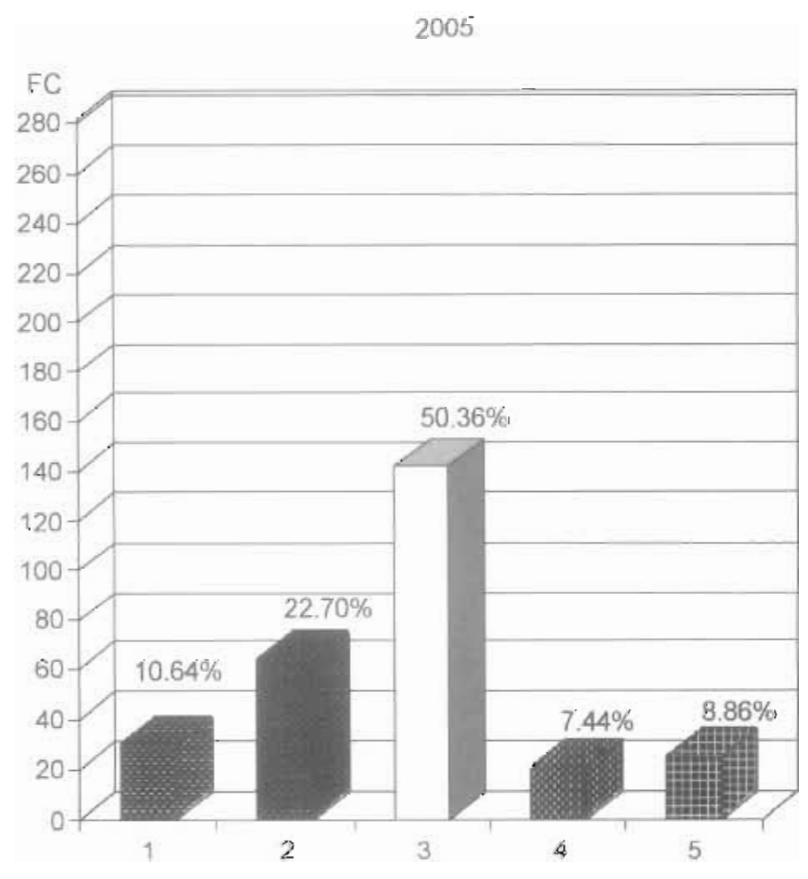

OBSERVACIONES: El 50.36\% de los alumnos dicen que a veces hacen ejercicio porque otras veces están cansados(as) y el 7.44\% opinan que nunca hacen ejercicio porque no les interesa mantener su Autocuidado y porque no tienen tiempo. 
GRÁFICA N²

DISTRIBUCIÓN DE LA OPINIÓN DE LOS ESTUDIANTES DE PRIMER INGRESO, EN TORNO A CÓMO CONSIDERAN SU ALIMENTACIÓN PARA MANTENER SU AUTOCUIDADO, EN LA ESCUELA NACIONAL DE ENFERMERIA Y OBSTETRICIA, EN MÉXICO, D.F.

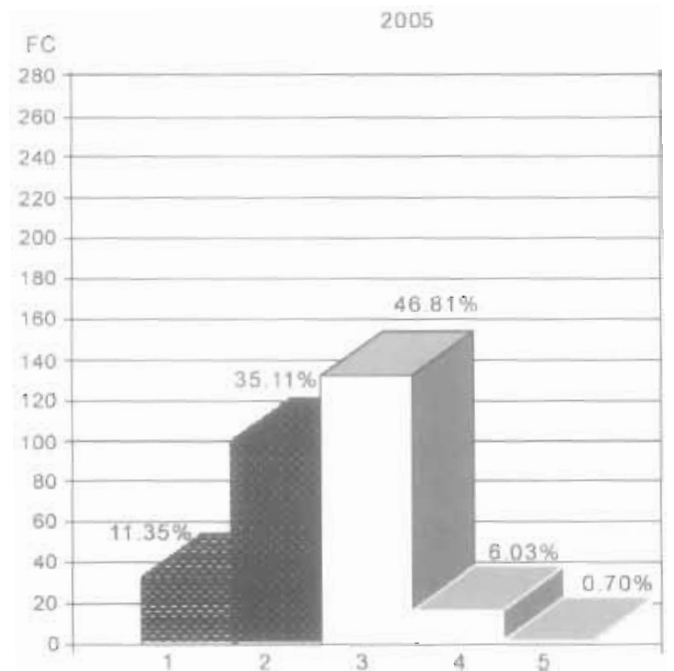

OBSERVACIONES: EI $46.81 \%$ de los alumnos dicen tener una alimentación regular ya que no se fijan mucho en to que comen y el $6.03 \%$ opinan que tienen una pésina alimentación ya que no tienen una dieta balanceada, no cuidan lo que comen y comen cuando pueden.

\section{GRÁFICA N³}

DISTRIBUCIÓN DE LA OPINIÓN DE LOS ESTUDIANTES DE PRIMER INGRESO, EN TORNO A SI PREVIENEN LAS ENFERMEDADES, EN LA ESCUELA NACIONAL DE ENFERMERIA Y OBSTETRICIA, EN MÉXICO, D.F.

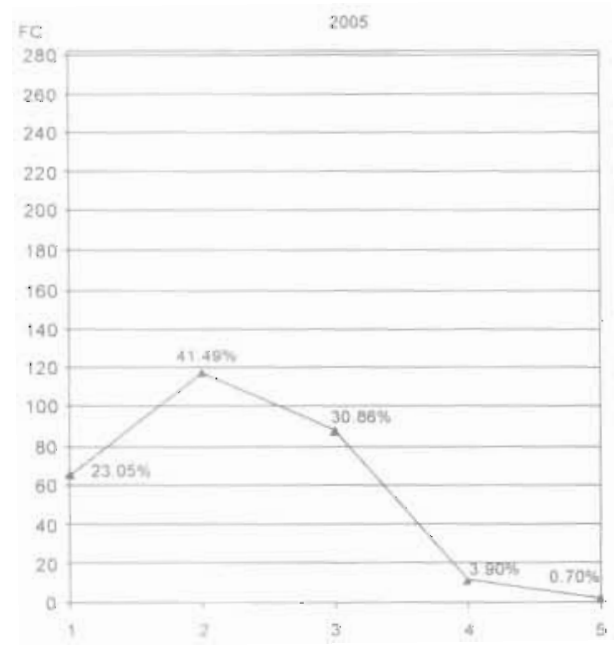

OBSERVACIONES: El $41.49 \%$ de los alumnos dicen que la mayoria de veces previenen las enfermedades acudiendo al médico por lo menos una vez. al ano y el $3.90 \%$ opinan que nunca previenen las enfermedades ya que son personas fuertes y no se enferman y si éstas llegan, pues ni modo.

\section{GRÁFICA N ${ }^{\circ} 4$}

DISTRIBUCIÓN DE LA OPINIÓN DE LOS ESTUDIANTES DE PRIMER INGRESO, EN TORNO A SI REALIZAN ACTIVIDADES RECREATIVAS PARA MANTENER SU AUTOCUIDADO, EN LA ESCUELA NACIONAL. DE ENFERMERIA Y OBSTETRICIA, EN MÉXICO, D.F.

2005

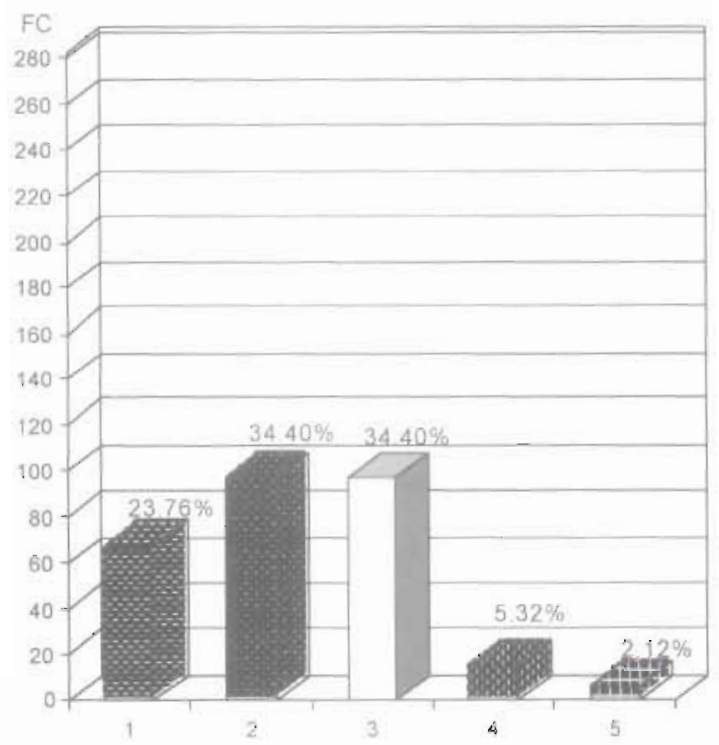

OBSERVACIONES: EI 34.40\% de los alumnos dicen que la mayoria de las veces buscan actividades recreativas para combinarlas con sus horas de estudio, otro $34.40 \%$ dicen que a veces hacen actividades recreativas pero otras veces no. io hacen porque no tienen tiempo y el 5.32\% opinan que nunca tienen tiempo de realizar actividades recreativas ya que saliendo de la Escuela, tienen que trabajar y hacer otras actividades durante el dia

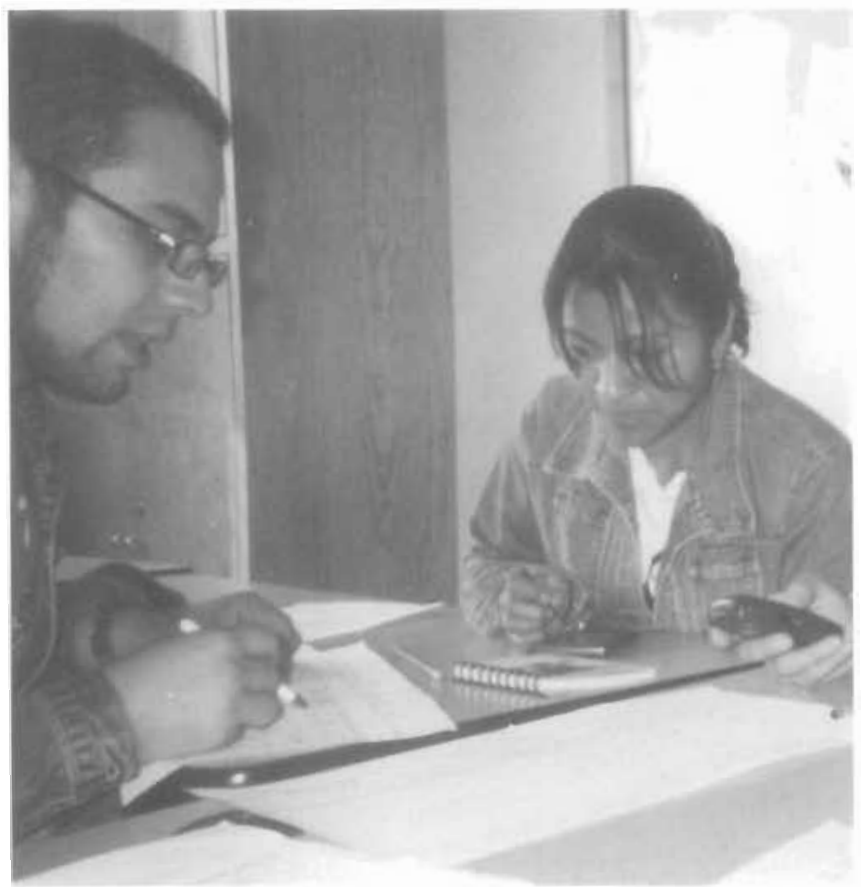




\section{SUGERENCIAS}

Es necesario para los alumnos del primer semestre:

- Realizar ejercicio cuando menos 3 veces por semana sin descuidar sus actividades educativas para tratar de mantenerse en forma.

- Prevenir enfermedades porque así gozarán de una buena calidad de vida ya que el no cuidar su aseo personal traerá consigo problemas a la salud

- Procurar consumir los alimentos en forma equilibrada

- Practicar el aseo personal de una manera constante para tener un bienestar en los aspectos biológicos, culturales y sociales.

- Tener el hábito de no desvelarse continuamente ya que eso provocará que exista un mal aprovechamiento del tiempo para realizar adecuadamente las actividades.

- Procurar mantener un descanso que permita contar con la suficiente energía para realizar las actividades cotidianas

- Acudir por lo menos dos veces al año al Dentista para prevenir caries

- Tener actividades que permitan distraerse y al mismo tiempo, desarrollar sus habilidades para alcanzar un mayor grado de Autocuidado

- Proporcionar información para todos aquellos que tienen un déficit de Autocuidado, para dar a conocer cuáles son los medios para tener un mejor Autocuidado
- Realizar actividades recreativas cuando menos dos veces a la semana, sin descuidar sus actividades educativas para mantener su Autocuidado

- Comer tranquilamente procurando masticar muy bien los alimentos en cada bocado, para mantener una buena digestión.

\section{REFERENCIAS BIBLIOGRÁFICAS}

FRIAS, Antonio. Enfermeria comunitario. Ed. Masson. Madrid, 2002. 502 pp.

FUERST, Elianor. Principios fundamentales de Enfermerio. Ed. La prensa Médica Mexicana. $13^{\circ} \mathrm{ed}$. México, 1958.523 pp.

HENDERSON, Virginia. Enfermerio, técnica y práctica. Ed. La prensa Médica Mexicana. $3^{\circ}$ ed. México, 1987. 484 pp.

HIGASHIDA, Bertha. Educación para la salud. Ed. Interamericana. México, 302 pp.

KLAINBERG, Marilyn y Stephen Molzemer. Salud comunitario. Ed McGraw Hill, Bogotá, 1996.

OREM, Dorotea. Modelo de Oreom. Ed. Masson. $4^{\circ}$ ed. Madrid, 1993 423 PP.

OREM, Dorothea. Nórmos, practices de Enfermería. Ed. Pirámide Madrid, 1983. 294 pp.

OREM, Dorotea. Conceptos de Enfermeria en la práctica. Ed. Masson. Madrid, 2000. 502 Pp.

POTTER, Patricia y Anne Griffin. Fundamentos de Enfermería. Ed. Harcourt. $5^{\circ}$ ed. Madrid, 2002. 985 pp.

POWELL, Don. Un año de consejos para la salud. Ed. Patria. México, 1992. 436 pp.

WORLEY, Eloise Enfermería dinica y farmacologia. Ed. Manua Moderno. $3^{\circ}$ ed. México, 1985. 312 pp.

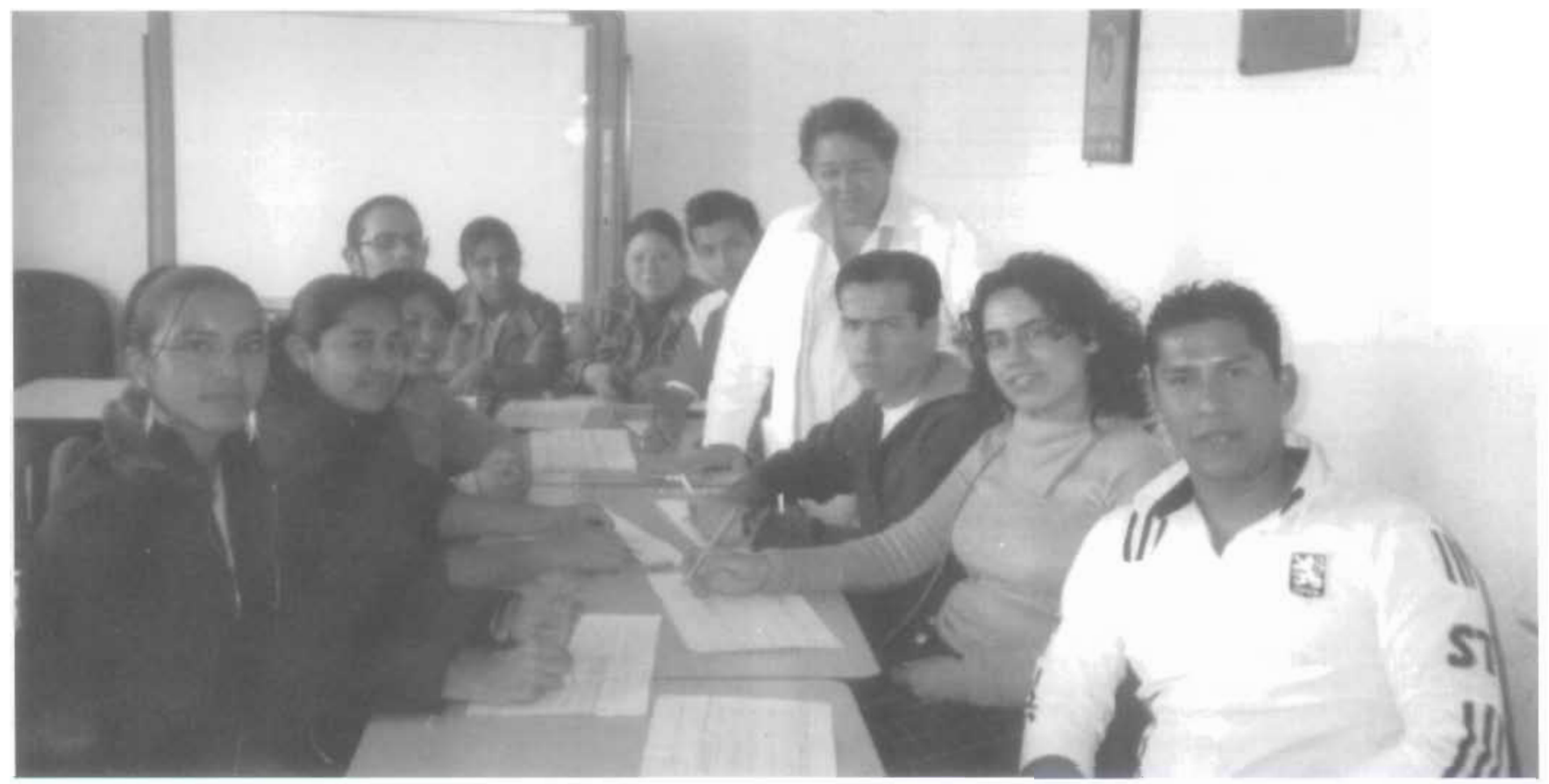

